\title{
Multiple Docetaxel Retreatments Without Prednisone for Metastatic Castration-Resistant Prostate Cancer in the Docetaxel-Only Era: Effects on PSA Kinetics and Survival
}

\author{
Agnieszka Maj-Hes · Tibor Szarvas · Sabina Sevcenco • \\ Gero Kramer
}

Received: March 7, 2021 / Accepted: May 6, 2021 / Published online: May 27, 2021

(c) The Author(s) 2021

\section{ABSTRACT}

Introduction: This study aimed to assess the effects of multiple docetaxel (DOC) treatments on prostate-specific antigen (PSA) kinetics and survival among patients with metastatic castration-resistant prostate cancer (mCRPC) who were sensitive to first-line DOC and received no other life-prolonging agents. To eliminate the effect of cortisone on serum PSA, only patients who were treated without prednisone were included.

Methods: This IRB-approved retrospective study evaluated 52 patients with MCRPC who were retreated using DOC after first-line DOC (without prednisone in both cases), based on a PSA response of $>50 \%$ and no radiographic progression. Twenty-three PSA-based factors, including static and kinetic PSA measures, were

A. Maj-Hes - T. Szarvas · S. Sevcenco ·

G. Kramer $(\square)$

Department of Urology, Medical University of

Vienna, Währinger Gürtel 18-20, 1090 Vienna, Austria

e-mail: gero.kramer@meduniwien.ac.at

\section{T. Szarvas}

Department of Urology, West German Cancer Center, University of Duisburg-Essen, Duisburg, Germany

T. Szarvas

Department of Urology, Semmelweis University, Budapest, Hungary evaluate for their ability to predict overall survival (OS)

Results: The patients received 688 cycles of DOC in 143 series, including 91 courses of retreatments ( 1 cycle: 28 patients, 2 cycles: 14 patients, 3 cycles: 8 patients, 4 cycles: 1 patient, and 7 cycles: 1 patient). The median overall number of cycles per patient was 12 (range: 7-31). The median durations of the first, second, and third holidays were 18 weeks (6-60 weeks), 16 weeks (3-44 weeks), and 17 weeks (8-51 weeks), respectively. The median OSs were 22 months (10.5-70 months) after the first DOC treatment and 14 months (3-65 months) after the second DOC treatment. The $>50 \%$ PSA decline rate was $48 \%$ after retreatment. Short treatment holidays ( $<3$ months) were associated with shortened OS $(p=0.01)$. In the multivariate analysis, a 25\% PSA increase over the nadir was the strongest predictor of survival (HR: 3.20, 95\% CI: 1.47-6.99, $p=0.003$ ).

Conclusions: DOC retreatment without prednisone had anti-tumor activity in a considerable proportion of mCRPC cases that were initially sensitive to first-line DOC. A 25\% PSA increase over the nadir might predict acquired DOC resistance.

Keywords: DOC; DOC retreatment; mCRPC; OS; PSA 


\section{Key Summary Points}

DOC retreatment without prednisone had anti-tumor activity in a considerable proportion of mCRPC cases that were initially sensitive to first-line DOC.

A 25\% PSA increase over the nadir might predict acquired DOC resistance.

Multiple DOC retreatments without prednisone had sustained activity in select patients with mCRPC.

Type I PSA progression (a PSA increase of $\geq$ $25 \%$ from the nadir) had the greatest ability to predict OS, which may facilitate the identification of patients who are most likely to benefit from non-DOC second-line therapies.

\section{DIGITAL FEATURES}

This article is published with digital features, including a summary slide, to facilitate understanding of the article. To view digital features for this article go to https://doi.org/10.6084/ m9.figshare.14541378.

\section{INTRODUCTION}

Since 2004 the standard first-line treatment option for metastatic castration-resistant prostate cancer (mCRPC) has been 3 weekly series of docetaxel (DOC) plus prednisone providing a survival benefit of 2-3 months compared to mitoxantrone plus prednisone [1].

The current DOC treatment is administered in a single series of 6-10 treatment cycles, as patients with CPRC have broad variations in their sensitivities to DOC. Some patients progress early during the first series of DOC treatment and can be considered DOC-resistant, while other patients complete treatment without experiencing progression and are considered DOC-sensitive. Despite their favorable response to first-line therapy, DOC-sensitive patients are not routinely considered for further DOC retreatment, although these patients will clearly experience progression after discontinuing DOC therapy [2].

Previous studies have confirmed the activity and feasibility of a single DOC retreatment for patients who have successfully completed firstline DOC treatment [3-6]. These results clearly suggest that a considerable portion of CRPCs remain sensitive to DOC after first- and secondline treatment, which supports the use of further DOC retreatments until the development of resistance [7]. During the last 7 years first-line docetaxel treatment in mCRPC has lost its importance as a stand-alone position as several other effective first-line treatments for MCRPC [e.g., abiraterone (2013), enzalutamide (2014) and sipuleucel-T immunotherapy (2010)] have been approved [8-10].

Moreover, there are no prospective data to guide patient selection criteria for the first-line treatments in mCRPC. Thus, DOC rechallenge could be useful as a sandwich treatment for mCRPC or after early treatment using DOC plus hormonal treatment in the hormone-sensitive metastatic setting [11-13].

Moreover, it remains critical to detect DOC resistance as early as possible in order to switch patients to other effective therapies.

The present study aimed to assess the effects and feasibility of multiple DOC retreatments until the development of drug resistance. Furthermore, we analyzed static and kinetic PSAbased factors for their ability to predict therapy resistance and survival. To eliminate the effect of cortisone on serum PSA, we only included patients with primary treatment and retreatment using DOC without prednisone.

\section{METHODS}

This retrospective study was approved by our local ethics committee (EK-Nr. 426/2009 Ethic Committee of Medical University of Vienna). Between 2003 and 2008, 52 patients with DOCsensitive mCRPC underwent at least one DOC retreatment (i.e., at least two series) at our center. Only patients who had received DOC 
Table 1 Patients' characteristics

\begin{tabular}{ll}
\hline Variable & Value (\% or range) \\
\hline Total number of patients & 52 \\
Age at diagnosis median (range) years & $68(47-86)$ \\
Previous prostatectomy & 20 \\
Previous external beam radiotherapy & 5 \\
Interval from diagnosis to CRPC (months) & $64.3(1-72)$ \\
Interval from hormone therapy to CRPC & $47(1-172)$ \\
Performance status & \\
0 & $30(58)$ \\
1 & $16(31)$ \\
2 & $6(11)$ \\
3 & $0(0)$ \\
PSA at enrollment (ng/ml) & $79(3-866)$ \\
Bone metastasis & $38(92)$ \\
Lymph node metastasis (> 2 cm) & $4(8)$ \\
Soft tissue lesions (lung/liver) & $1(2)$ \\
Bone mets and lymph node mets & $9(17)$ \\
Clinical subtypes according to prostate cancer Working Group Criteria II & \\
Rising PSA and no detectable metastatic disease & $0(0)$ \\
Nodal spread and no evident bone or visceral disease & $4(8)$ \\
Bone disease with nodal disease and no evident visceral spread & $9(17)$ \\
Bone disease w/o nodal disease and no evident visceral spread & $38(73)$ \\
Visceral metastases with spread at other sites & $1(2)$ \\
Visceral metastases without spread at other sites & 0 \\
\hline & \\
\hline
\end{tabular}

without prednisone were included, and patients who received non-DOC life-prolonging agents were excluded. The patients' characteristics are shown in Table 1 . Before each retreatment, a complete work-up with at least a bone scan and computed tomography of the abdomen and thorax was performed. In addition, complete blood chemistry testing was performed, which examined PSA levels, testosterone levels, and blood counts. Castration resistance was defined as clinical progression during androgen ablation therapy, according to the Prostate Cancer Clinical Trials Working Group Criteria II [14]. Patients were considered DOC-sensitive after completing first-line DOC treatment; they exhibited a PSA decline of $\geq 50 \%$ without radiographic progression. PSA declines were defined using the Prostate Cancer Clinical Trials Working Group Criteria II, while radiographic progression was assessed according to the RECIST criteria [15]. Patients received intermittent intravenous DOC at a standard dosage of 
$75 \mathrm{mg} / \mathrm{m}^{2}$ every 3 weeks without prednisone (standard dose: $5 \mathrm{mg}$ twice daily). For DOCsensitive patients, retreatment using DOC (second or higher series) was offered until the appearance of radiographic progression during DOC treatment. Treatment holidays were provided between each series, which consisted of 2-6 treatment cycles. Imaging was performed at baseline, at the end of each series, and during the treatment holidays.

During the treatment holidays, three weekly PSA measurements and clinical examinations were performed. In addition, PSA levels were assessed at baseline, on days 3 and 7 of each cycle, and then every 3 weeks. According to the Prostate Cancer Working Group Criteria II, we used three different methods to define PSA progression: (1) type I PSA progression was calculated as an increase of $\geq 25 \%$ from the nadir, (2) type II PSA progression was based on a PSA value above the baseline level (independent of the patient's treatment or holiday status), and (3) type III PSA progression was defined as a PSA nadir that exceeded the baseline value for the first DOC treatment. We also calculated the PSA doubling time and PSA velocity for each holiday as well as the absolute PSA levels at the start of each series, at 12 weeks after the last cycle, and at the PSA nadir for each series. Maximum PSA declines (as absolute values and percentages of the baseline value) during each series and at 12 weeks after the last cycle were categorized as $<30 \%$ and $<50 \%$. PSA progression at 12 weeks was defined as a $>25 \%$ PSA increase relative to the baseline level for each series.

As patient survival is considered the most reliable endpoint for predicting chemotherapy effectiveness, we used overall survival (OS) as the primary outcome. The secondary outcome was defined as the ability of the various PSArelated factors to predict OS.

\section{Statistical Analysis}

Paired group comparisons were performed using the nonparametric two-sided Wilcoxon ranksum test. Survival analyses were performed using Kaplan-Meier curves, the log-rank test, and univariable Cox analyses. Factors with continuous values were analyzed as a continuous variable and as a categorical variable that was dichotomized using the median value. The Cox proportional hazards regression model was used for the multivariable analysis, using variables that were significantly associated with OS in the univariable analyses $(p \leq 0.05)$. All statistical analyses were two-sided and used a significance level of 0.05. All analyses were performed using IBM SPSS software (version 19.0; IBM Corp., Armonk, NY).

\section{RESULTS}

Between 2003 and 2008, 52 patients with mCRPC considered docetaxel sensitive without experiencing disease progression after first-line DOC underwent at least one DOC retreatment.

Patient's characteristics at baseline are outlined in the Table 1.

The total number of retreatments was 91, with 688 cycles in 143 series (2 series: 28 patients, 3 series: 14 patients, 4 series: 8 patients, 5 series: 1 patient, 8 series: 1 patient). The median overall number of cycles per patient was 12 (range: 7-31). The median durations of the first, second, and third holidays were 18 weeks (range: 6-60 weeks), 16 weeks (range: 3-44 weeks), and 17 weeks (range: 8-51 weeks), respectively.

All 52 patients died, with 49 patients dying because of the prostate cancer and 3 dying because of other causes. The median survival times were 85 weeks (range: 42-280 weeks) after the baseline DOC treatment and 54 weeks (range: 12-260 weeks) from the start of the first retreatment (second series). Thirty-three patients (63.4\%) developed progression during the DOC chemotherapy based on the RECIST criteria, with a median latency of 54 weeks (range: 33-187 months). The median progression-free survival time was 65 weeks (range: 33-230 weeks). The biochemical response rate (a PSA decline of $\geq 50 \%$ ) was detected in 44 of the 91 retreatments (48\%) (Fig. 1). 

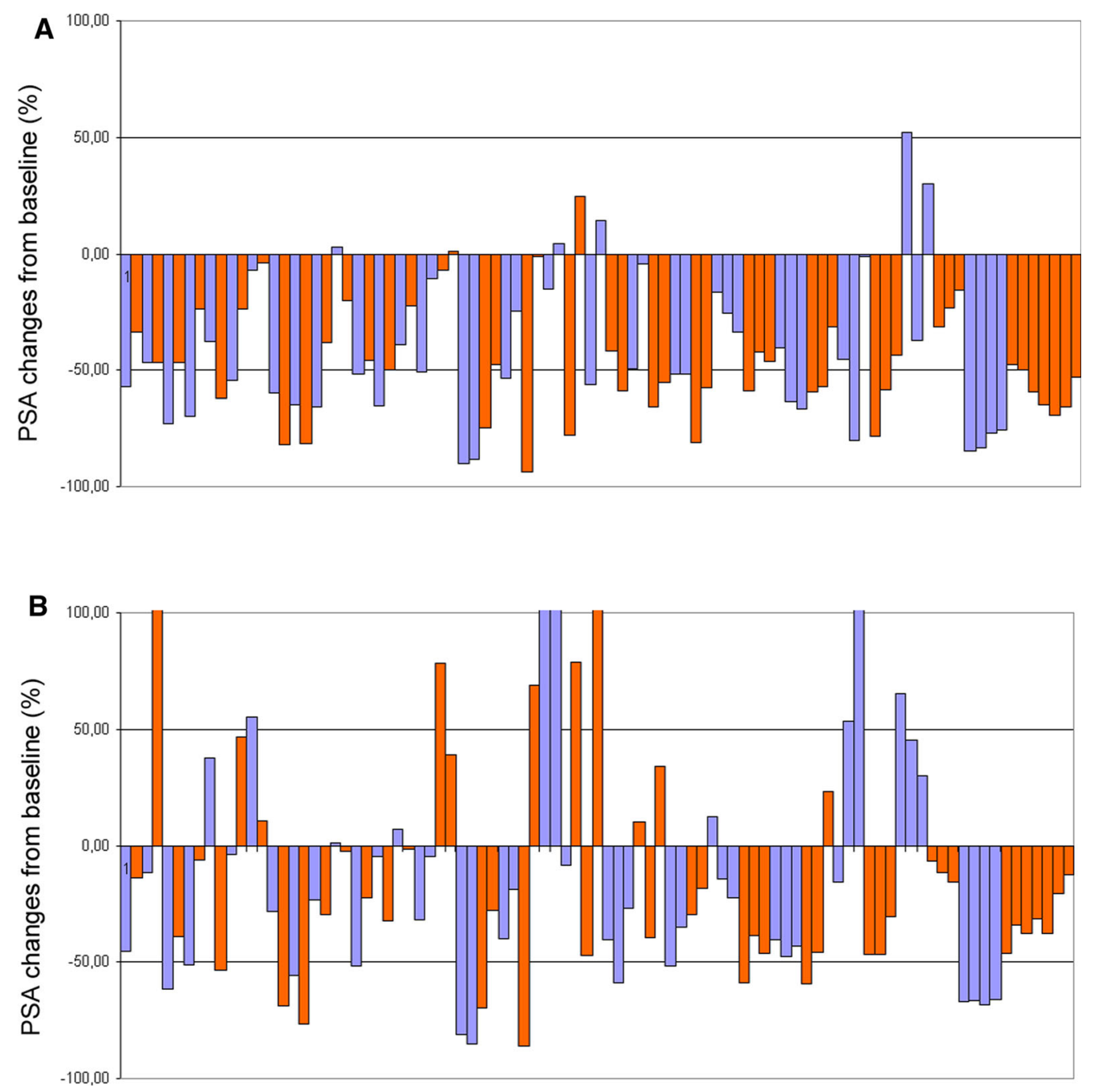

Fig. 1 Waterfall plots of (a) the maximal PSA decline and (b) the PSA decline at 12 weeks compared to the baseline levels for all 52 patients (91 DOC retreatments).

\section{Associations Between the Patients' Baseline Characteristics and OS}

Table 2 shows the associations of OS with various baseline characteristics, including age, primary local therapy (external beam radiotherapy, radical prostatectomy, or lymphadenectomy), ECOG performance status, presence of bone metastasis with or without lymph node metastasis, and the number of bone metastases at baseline (before the first DOC series). However, only the presence of $>6$ bone metastases was significantly associated
Retreatments for the same patient are indicated in the same color (e.g., the last patient had 7 DOC treatments, which are indicated in red)

with a poor prognosis $(p=0.022)$. Treatment holidays that were $<3$ months were associated with shorter OS $(p=0.011)$. No association was observed when the cut-off value was extended to 6 months $(p=0.86)$.

\section{Associations Between PSA Levels Before DOC Retreatment and OS}

A poor prognosis was significantly associated with PSA levels at the start of each series $(p=0.011)$ and the absolute PSA nadir during DOC therapy $(p=0.003)$. Shorter OS was 
Table 2 Associations of baseline characteristics with patient survival

\begin{tabular}{llll}
\hline & \multicolumn{2}{l}{ Cox univariable analysis } \\
\cline { 2 - 4 } & HR & $\mathbf{9 5 \%}$ CI & $\boldsymbol{p}$ \\
\hline Age $(>$ 68 years) & 0.909 & $0.521-1.585$ & 0.736 \\
Primary local treatment (HIFU or RPE) & 0.926 & $0.533-1.610$ & 0.786 \\
Former lymphadenctomy & 0.680 & $0.380-1.219$ & 0.196 \\
ECOG (0 vs. 1-2) & 1524 & $0.858-2.707$ & 0.151 \\
Bone disease with nodal disease and no visceral spread & 1756 & $0.828-3.721$ & 0.142 \\
Bone disease w/o nodal disease and no visceral spread & 1084 & $0.583-2.015$ & 0.798 \\
Presence of lymph node metastases $>$ 2 cm & 0.842 & $0.429-1.653$ & 0.617 \\
Presence of bone metastases & 2187 & $0.766-6.249$ & 0.144 \\
More than 6 bone lesions & 2181 & $1.119-4.251$ & 0.022 \\
\hline
\end{tabular}

significantly associated with high PSA levels at 12 weeks after the last therapy cycle $(p=0.003)$ (Table 3).

\section{Associations Between PSA Kinetics and OS}

The PSA kinetic variables were evaluated for the 91 DOC retreatments, with survival defined as the interval between the start of a given series and the patient's death. The maximum PSA declines in each series were calculated (median: $49.6 \mathrm{ng} / \mathrm{ml}$, range: -94 to $52 \mathrm{ng} / \mathrm{ml}$ ) and were associated with OS if the maximum decline was treated as a continuous variable $(p=0.001)$ (Table 3). Similarly, high PSA declines at 12 weeks after the last therapy cycle were associated with shorter OS $(p=0.003)$. In contrast, relative PSA declines $(>30 \%$ or $>50 \%$ of the baseline PSA levels) did not significantly predict OS ( $p=0.07$ and $p=0.37$, respectively). A high PSA doubling time and low PSA velocity during the previous treatment holiday (as continuous variables) were associated with a favorable prognosis $(p=0.019$ and $p=0.006$, respectively).

In 44 of the 91 retreatments (48\%), type I PSA progression was noted during the DOC therapy and was associated with reduced OS $(p=0.001)$ (Fig. 2). Type II PSA progression was observed in 50 of 52 patients. As this type of PSA progression is not necessarily related to the treatment series, we categorized the cases according to whether the type II progression occurred during a treatment series or holiday. PSA type II progression during the previous treatment holiday was associated with shorter OS $(p=0.001)$, but not when it occurred during DOC therapy $(p=0.43)$. Type III PSA progression was associated with poor OS $(p=0.020)$. PSA progression at 12 weeks was marginally associated with DOC resistance $(p=0.08)$.

When all PSA-related variables with predictive value in the univariable analyses were included in the multivariable analysis, the strongest independent predictor of OS was the occurrence of type I PSA progression (hazard ratio: 3.202, 95\% confidence interval: 1.466-6.991, $p=0.003$ ) (Table 3).

\section{DISCUSSION}

Before the introduction of novel life-prolonging agents, several studies demonstrated that DOC retreatments were feasible and active for patients who responded to first-line DOC [2-7, 16-19]. Similar to our results, Eymard et al. reported a PSA response rate of $>50 \%$ after DOC re-challenge among 24 of 50 patients (48\%), with a median OS of 16 months from the 
Table 3 Associations of PSA-based parameters with patient survival

\begin{tabular}{|c|c|c|c|c|c|c|c|}
\hline & & \multicolumn{3}{|c|}{ Cox univariable analysis } & \multicolumn{3}{|c|}{ Cox multivariable analysis } \\
\hline & & HR & $95 \% \mathrm{CI}$ & $p$ & HR & $95 \% \mathrm{CI}$ & $p$ \\
\hline PSA at start of the series & Cont. & 1000 & $1.000-1.000$ & 0.293 & & & \\
\hline PSA at start of the series & Categ. & 1757 & $1.137-2.715$ & 0.011 & 1002 & $0.425-2.363$ & 0.997 \\
\hline PSA nadir in the given series & Cont. & 1000 & $1.000-1.000$ & 0.540 & & & \\
\hline PSA nadir in the given series & Categ. & 1940 & $1.254-3.000$ & 0.003 & 1247 & $0.395-3.934$ & 0.706 \\
\hline PSA at 12 weeks & Cont. & 1000 & $1.000-1.000$ & 0.885 & & & \\
\hline PSA at 12 weeks & Categ. & 2048 & $1.325-3.166$ & 0.001 & 1917 & $0.493-7.453$ & 0.347 \\
\hline $\begin{array}{l}\text { PSA decline }(>50 \%) \text { in the } \\
\text { given series }\end{array}$ & Categ. & 0.827 & $0.545-1.255$ & 0.373 & & & \\
\hline $\begin{array}{l}\text { PSA decline }(>30 \%) \text { in the } \\
\text { given series }\end{array}$ & Categ. & 0.644 & $0.400-1.039$ & 0.071 & & & \\
\hline $\begin{array}{l}\text { Absolute PSA decline in the } \\
\text { given series }\end{array}$ & Cont. & 1003 & $1.001-1.004$ & 0.001 & 1002 & $1.000-1.004$ & 0.038 \\
\hline $\begin{array}{l}\text { Absolute PSA decline in the } \\
\text { given series }\end{array}$ & Categ. & 1297 & $0.828-2.033$ & 0.256 & & & \\
\hline PSA decline at 12 weeks & Cont. & 1004 & $1.000-1.008$ & 0.081 & & & \\
\hline PSA decline at 12 weeks & Categ. & 1956 & $1.252-3.054$ & 0.003 & 0.857 & $0.397-1.849$ & 0.693 \\
\hline $\begin{array}{l}\text { PSA at baseline/PSA at } \\
12 \text { weeks (ratio) }\end{array}$ & Cont. & 1493 & $0.962-2.317$ & 0.074 & & & \\
\hline $\begin{array}{l}\text { PSA at baseline/PSA at } \\
12 \text { weeks (ratio) }<25 \%\end{array}$ & Categ. & 1666 & $0.927-2.996$ & 0.088 & & & \\
\hline PSADT in previous holiday & Cont. & 1002 & $0.974-1.031$ & 0.880 & & & \\
\hline PSADT in previous holiday & Categ. & 0.606 & $0.398-0.922$ & 0.019 & 0.189 & $0.012-3.051$ & 0.240 \\
\hline $\begin{array}{l}\text { PSA velocity in previous } \\
\text { holiday }\end{array}$ & Cont. & $6.35 \times 10^{4}$ & $1.195-3.37 \times 10^{9}$ & 0.046 & $2.39 \times 10^{3}$ & $0.00-3.23 \times 10^{9}$ & 0.513 \\
\hline $\begin{array}{l}\text { PSA velocity in previous } \\
\text { holiday }\end{array}$ & Categ. & 1803 & $1.181-2.754$ & 0.006 & 0.264 & $0.016-4.291$ & 0.349 \\
\hline $\begin{array}{l}\text { Type I PSA progr. in the given } \\
\text { series }\end{array}$ & Categ. & 4398 & $2.689-7.195$ & 0.001 & 3202 & $1.466-6.991$ & 0.003 \\
\hline $\begin{array}{l}\text { Type II PSA progr. in previous } \\
\text { holiday }\end{array}$ & Categ. & 2697 & $1.489-4.885$ & 0.001 & 1466 & $0.639-3.362$ & 0.367 \\
\hline $\begin{array}{l}\text { Type II PSA progr. in a given } \\
\text { series }\end{array}$ & Categ. & 0.727 & $0.328-1.612$ & 0.433 & & & \\
\hline $\begin{array}{l}\text { Type II PSA progr. in prev.hol. } \\
\text { or in the givens series }\end{array}$ & Categ. & 1416 & $0.806-2.486$ & 0.226 & & & \\
\hline
\end{tabular}


Table 3 continued

\begin{tabular}{|c|c|c|c|c|c|c|c|}
\hline & & \multicolumn{3}{|c|}{ Cox univariable analysis } & \multicolumn{3}{|c|}{ Cox multivariable analysis } \\
\hline & & $\overline{\text { HR }}$ & $95 \% \mathrm{CI}$ & $p$ & $\overline{\text { HR }}$ & 95\% CI & $p$ \\
\hline $\begin{array}{l}\text { Type III PSA progr. in a given } \\
\text { series }\end{array}$ & Categ. & 1795 & $1.096-2.940$ & 0.020 & 0.591 & $0.258-1.352$ & 0.231 \\
\hline
\end{tabular}

PSA prostate-specific antigen, categ. categorical variable, cont. continuous variable

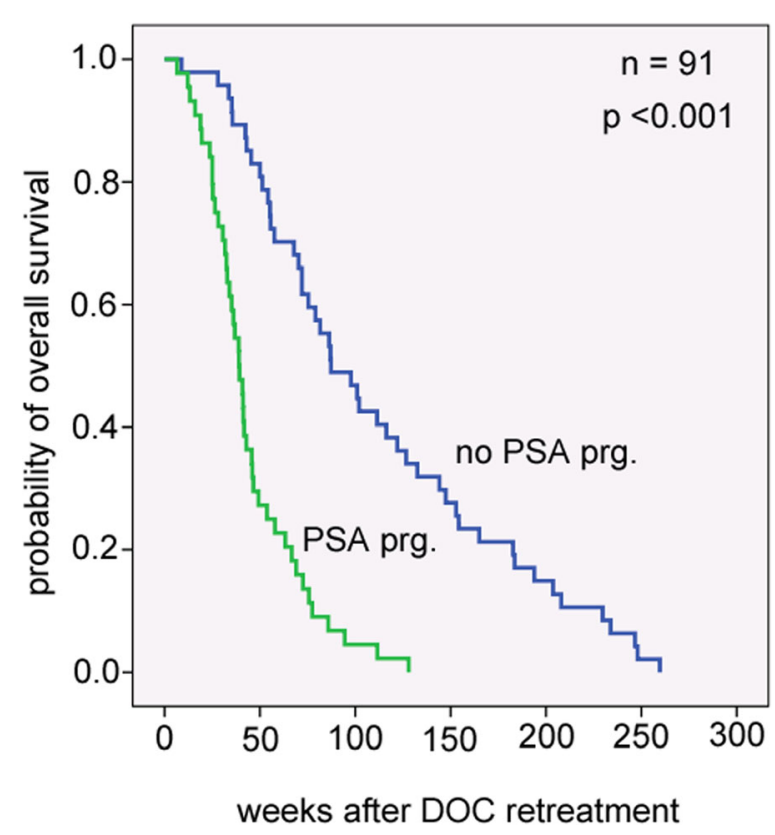

Fig. 2 Kaplan-Meier estimates of overall survival according to the occurrence of type I PSA progression during the retreatment series

DOC reinduction [2]. Loriot and colleagues showed in a retrospective series of 39 mCRPC patients that a treatment-free interval $>3$ months between the first docetaxel-sequence and rechallenge is predictive for an improved OS [3]. These results go along with the data from Oudard et al. who found a median OS of 20.4 months for patients with an initial response of 6 months versus 17.1 months for patients with an initial response of 3-6 months and 15.7 months for the patients with an initial response $<3$ months [16].

Caffo et al. examined 46 patients who underwent DOC rechallenge and detected a high PSA response rate (66\%) and prolonged OS (32 months from the first-line DOC treatment) [5]. In that study, a treatment holiday duration of $\geq 23$ weeks and PSA doubling time during the previous DOC course were predictors of a rechallenge response [5]. However, only 26 of the 46 patients had died at the time of the data analysis compared to all patients in the present study. Previous studies have indicated that PSA progression at 12 weeks and a $<30 \%$ PSA decline were predictors of poor OS after first-line DOC treatment of CRPC [20-23]. However, the present study only revealed marginal associations of both PSA changes with shorter OS ( $p=0.08$ and $p=0.07$, respectively), which suggests that predictors from first-line DOC therapy only have modest predictive value during DOC retreatments. Heck et al. have concluded that a PSA decline of $<50 \%$ during first-line DOC therapy might predict the effectiveness of second-line DOC treatment [7]. Although we only examined patients who exhibited a biochemical response $(\mathrm{a}>50 \%$ PSA decline) to first-line DOC therapy, we analyzed the predictive value of a $>50 \%$ PSA decline in the retreatment series and found no association with survival. This finding challenges Heck et al.'s assertion that PSA decline is a universal predictive factor during DOC retreatment. In the present study, the strongest predictor of DOC failure based on OS was type I PSA progression (according to the PCWG II criteria). Thus, a PSA increase of $\geq 25 \%$ from the nadir may be useful for identifying the optimal time to switch from DOC retreatment to another lifeprolonging agent. Our patients had received DOC monotherapy without prednisone, while practically all studies of MCRPC have evaluated chemotherapy with concurrent daily 
corticosterone [1]. However, the clinical effectiveness of prednisone plus DOC remains unclear. For example, a phase III trial of mitoxantrone/prednisone compared to daily prednisone alone detected a $>50 \%$ PSA decline in $24 \%$ of patients, with a progression-free survival of 4.1 months in the prednisone group [24].

Furthermore, data from the CHAARTED phase III trial (6 cycles of DOC every 3 weeks without corticosteroids for metastatic castration-naive prostate cancer) revealed a significant survival benefit in patients with highvolume tumors [13]. Thus, the efficacy of adding prednisone to DOC treatment remains unclear. Interestingly, Teply et al. from Johns Hopkins reported retrospective data comparing DOC with and without prednisone for MCRPC. In that study, prednisone was associated with a reduced risk of progression, but not if previous prednisone-containing regimens had been administered (e.g., abiraterone) [25]. That finding appears to validate our use of DOC without prednisone. In addition, prednisone may activate androgen receptors and drive the growth of prostate cancer in addition to other mutations that can allow glucocorticoids to activate androgen receptors $[26,27]$.

Nevertheless, a retrospective study by Oudard et al. found no difference in OS between patients who were rechallenged to docetaxel and patients who received non-taxane based therapy, but improved PSA response and symptom relief were associated with docetaxel rechallenge. Despite the development of novel approved therapies in the post-docetaxel setting, some patients may still be candidates for retreatment with docetaxel, but the docetaxelassociated cumulative toxicities have to be carefully considered [16].

There are some limitations using PSA as a therapy monitoring marker. First, some prostate cancers (e.g., the neuroendocrine type) may produce less PSA, which can lead to low PSA levels in highly malignant prostate cancers. Second, there is a known phenomenon that involves an initial PSA elevation above the baseline, followed by a PSA decline, which can occur in up to $10 \%$ of patients who receive hormonal or chemotherapy, although this flare- up does not affect survival [23]. In addition, therapy response (based on OS) is associated with the length of the progression-free period after the completion of first-line DOC therapy $[4,5,7]$.

Moreover, Thomas et al. revealed that partial PSA response at docetaxel rechallenge and treatment interval $>3$ months were the only independent predictive factors for OS [6].

In that context, an interval of $>3$ months after the last DOC course was associated with prolonged OS, and our data also confirm the predictive value of progression-free survival during DOC retreatment. Another limitation of the study besides the retrospective design is the lack of quality of life data. However, at least none of the patients in this real-world clinical setting discontinued docetaxel rechallenge because of side effects.

\section{CONCLUSIONS}

Multiple DOC retreatments without prednisone had sustained activity in select patients with mCRPC. Thus, this approach may be a reasonable treatment option for patients who complete first-line DOC treatment. Type I PSA progression (a PSA increase of $\geq 25 \%$ from the nadir) had the greatest ability to predict OS, which may facilitate the identification of patients who are most likely to benefit from non-DOC second-line therapies.

\section{ACKNOWLEDGEMENTS}

Funding. No funding or sponsorship was received for this study or publication of this article. The Rapid Service Fee was funded by the authors.Tibor Szarvas was supported by the János Bolyai Research Scholarship of the Hungarian Academy of Sciences. This work was supported by the National Research, Development and Innovation Office-NKFIH/FK 124431 and by the ÚNKP-20-5-SE-1 New National Excellence Program of the Ministry for Innovation and Technology from the source of the 
National Research, Development and Innovation Fund.

Authorship. All named authors meet the International Committee of Medical Journal Editors (ICMJE) criteria for authorship for this article, take responsibility for the integrity of the work as a whole, and have given their approval for this version to be published.

Authors' Contributions. Agnieszka Maj-Hes: concept and design of the study, drafting the manuscript.Tibor Szarvas: statistical analysis, drafting the manuscript.Sabina Sevcenco: concept of the study, drafting the manuscript. Gero Kramer: supervisor of the study, drafting the manuscript, concept and design of the manuscript.

Disclosures. Agnes Maj-Hes, Tibor Szarvas, Sabina Sevcenco, and Gero Kramer have no conflict of interest to declare

Compliance with Ethics Guidelines. All data analyzed were collected as part of routine diagnosis. This manuscript (retrospective study) is approved by local Ethics Committee of Medical University of Vienna (address: Borschkegasse 8b/E06) with reference number: 426/2009. This study was performed in accordance with the Heksinki Declaration of 1964 and its later amendments.

Data Availability. The manuscript has no associated data or the data will not be deposited.

Open Access. This article is licensed under a Creative Commons Attribution-NonCommercial 4.0 International License, which permits any non-commercial use, sharing, adaptation, distribution and reproduction in any medium or format, as long as you give appropriate credit to the original author(s) and the source, provide a link to the Creative Commons licence, and indicate if changes were made. The images or other third party material in this article are included in the article's Creative Commons licence, unless indicated otherwise in a credit line to the material. If material is not included in the article's Creative Commons licence and your intended use is not permitted by statutory regulation or exceeds the permitted use, you will need to obtain permission directly from the copyright holder. To view a copy of this licence, visit http://creativecommons.org/licenses/by$\mathrm{nc} / 4.0 /$.

\section{REFERENCES}

1. Tannock IF, De Witt R, Berry WR, Horti J, Pluzanska $\mathrm{A}$, Chi KN, et al. Docetaxel plus prednisone or mitoxantrone plus prednisone for advanced prostate cancer. N Engl J Med. 2004;351(15):1502-12.

2. Eymard JC, Oudard S, Gravis G, Ferrero JM, Theodore $\mathrm{C}$, Joly $\mathrm{F}$, et al. Docetaxel reintroduction in patients with metastatic castration-resistant docetaxel-sensitive prostate cancer: a retrospective multicentre study. BJU Int. 2010;106:974-8.

3. Loriot Y, Massard C, Gross-Goupil M, Di Palma M, Escudier B, Bossi A, et al. The interval from the last cycle of docetaxel-based chemotherapy to progression is associated with the efficacy of subsequent docetaxel in patients with prostate cancer. Eur J Cancer. 2010;46:1770-2.

4. Di Lorenzo G, Buonerba C, Faiella A, Rescigno P, Rizzo M, Autorino R, et al. Phase II study of docetaxel re-treatment in docetaxel-pretreated castration-resistant prostate cancer. BJU Int. 2011;107: 234-9.

5. Caffo O, Pappagallo G, Brugnara S, Caldara A, di Pasquale MC, Ferro A, et al. Multiple rechallenges for castration-resistant prostate cancer patients responding to first-line docetaxel: assessment of clinical outcomes and predictive factors. Urology. 2012;79:644-9.

6. Thomas C, Brandt MP, Baldauf S, Tsaur I, Frees S, Borgmann $\mathrm{H}$, et al. Docetaxel-rechallenge in castration-resistant prostate cancer: defining clinical factors for successful treatment response and improvement in overall survival. Intern Urol Nephrol. 2018;50:1821-7.

7. Heck MM, Thalgott M, Retz M, Wolf P, Maurer T, Nawroth R, et al. Rational indication for docetaxel rechallenge in metastatic castration-resistant prostate cancer. BJU Int. 2012;110:E635-40.

8. Ryan CJ, Smith MR, de Bono JS, Molina A, Logothetis CJ, de Souza O, et al. Abiraterone in metastatic prostate cancer without previous chemotherapy. N Engl J Med. 2013;368(2):138-48. 
9. Beer TM, Armstrong AJ, Rathopf DE, Loroit Y, Sternberg CN, Higano CS, et al. Enzalutamide in metastatic prostate cancer before chemotherapy. N Engl J Med. 2014;371(5):424-33.

10. Small EJ, Schellhammer PF, Higano CS, Redfern $\mathrm{CH}$, Nemunaitis JJ, Valone FH, et al. Placebo-controlled phase III trial of immunologic therapy with sipuleucel-T (APC8015) in patients with metastatic, asymptomatic hormone refractory prostate cancer. J Clin Oncol. 2006;24:3089-94.

11. Petrioli R, Francini E, Roviello G. Is there still a place for docetaxel rechallenge in prostate cancer? World J Clin Oncol. 2015;6:99-103.

12. James ND, Sydes MR, Clarke NW, Mason MD, Dearnaley DP, Spears MR, et al. Addition of docetaxel, zoledronic acid, or both to first-line-longterm hormone therapy in prostate cancer (STAMPEDE): survival results from an adaptive, multiarm, multistage, platform ranndomised controlled trial. Lancet. 2016;387(10024):1163-77.

13. Sweeney CJ, Chen YH, Carducci M, Liu G, Jarrard $\mathrm{DF}$, Eisenberger $\mathrm{M}$, et al. Chemohormonal therapy in metastatic hormone-sensitive prostate cancer. N Engl J Med. 2015;373:737-46.

14. Scher HI, Halabi S, Tannock I, Morris M, Sternberg $\mathrm{CN}$, Carducci MA, et al. Design and end points of clinical trials for patients with progressive prostate cancer and castrate levels of testosterone: recommendations of the Prostate Cancer Clinical Trials Working Group. J Clin Oncol. 2008;26:1148-59.

15. Husband JE, Schwartz LH, Spencer J, Ollivier L, King $\mathrm{DM}$, Johnson R, et al. Evaluation of the response to treatment of solid tumours: a consensus statement of the International Cancer Imaging Society. Br J Cancer. 2004;90:2256-60.

16. Oudard S, Kramer G, Caffo O, Creppy L, Loriot Y, Hansen $S$, et al. Docetaxel rechallenge after an initial good response in patients with metastatic castration-resistant prostate cancer. BJU Int. 2015;115: 744-52.

17. Bracarda S, Caserta C, Galli L, Carlini P, Pastina I, Sisani M, et al. Docetaxel rechallenge in metastatic castration-resistant prostate cancer: any place in the modern treatment scenario? An intention to treat evaluation. Future Oncol. 2015;11:3083-90.

18. Petrioli R, Roviello G, Fiaschi AI, Laera L, Miano ST, De Rubertis G, et al. Rechallenge of docetaxel combined with epirubicin given on a weekly schedule in advanced castration-resistant prostate cancer patients previously exposed to docetaxel and abiraterone acetate. Med Oncol. 2015;32:52.

19. Mountzios I, Bournakis E, Efstathiou E, Varkaris A, Wen S, Chrisofos $M$, et al. Intermittent docetaxel chemotherapy in patients with castrate-resistant prostate cancer. Urology. 2011;77:682-7.

20. Halabi S, Vogelzang NJ, Ou SS, Owzar K, Archer L, Small EJ. Progression-free survival as a predictor of overall survival in men with castrate-resistant prostate cancer. J Clin Oncol. 2009;27:2766-71.

21. Armstrong AJ, Garrett-Mayer E, Ou Yang YC, Carducci MA, Tannock I, de Wit R, et al. Prostatespecific antigen and pain surrogacy analysis in metastatic hormone-refractory prostate cancer. J Clin Oncol. 2007;25:3965-70.

22. Petrylak DP, Ankerst DP, Jiang CS, Tangen CM, Hussain MH, Lara PN Jr, et al. Evaluation of prostate-specific antigen declines for surrogacy in patients treated on SWOG 99-16. J Natl Cancer Inst. 2006;98:516-21.

23. Nelius T, Filleur S. PSA surge/flare-up in patients with castration-refractory prostate cancer during the initial phase of chemotherapy. Prostate. 2009;69:1802-7.

24. Berry W, Dakhil S, Modiano M, Gregurich M, Asmar L. Phase III study of mitoxantrone plus low dose prednisone versus low dose prednisone alone in patients with asymptomatic hormone refractory prostate cancer. J Urol. 2002;168(6):2439-43.

25. Teply BA, Luber B, Denmeade SR, Antonarakis ES. The influence of prednisone on the efficacy of docetaxel in men with metastatic castration-resistant prostate cancer. Prostate Cancer Prostatic Dis. 2016;19:72-8.

26. Matias PM, Carrondo MA, Coelho R, Thomaz M, Zhao XY, Wegg A, et al. Structural basis for the glucocorticoid response in a mutant human androgen receptor $(\mathrm{AR}(\mathrm{ccr}))$ derived from an androgen-independent prostate cancer. J Med Chem. 2002; 45:1439-46.

27. Krishnan AV, Zhao XY, Swami S, Brive L, Peehl DM, Ely KR, et al. A glucocorticoid-responsive mutant androgen receptor exhibits unique ligand specificity: therapeutic implications for androgen-independent prostate cancer. Endocrinology. 2002;143: 1889-900. 